\title{
Oral Health Care Access in New Hampshire
}

\author{
Eleanor M. Jaffee, Joan C. Widmer, and Lisa I. Speropolous
}

$\int \mathrm{a}$ ust as good oral health is essential to good overall health, poor oral health can increase the risk of a number of serious health problems, including stroke and cardiovascular disease. ${ }^{1}$ Access to oral health care is not universal, however. Barriers to care may be related to dental insurance accessibility and affordability, out-of-pocket costs, provider availability, distance to providers, and transportation to appointments. Certain populations such as children, the elderly, people with disabilities, and low-income families, particularly those in rural areas, may experience more barriers to care and therefore be more likely to experience poor oral health and its consequences. Among children, for example, poor oral health can lead to nutritional deficiencies, stunted growth, ${ }^{2}$ and poor academic performance resulting from school absences, ${ }^{3}$ and among older adults, to infection, pain, and poor quality of life. ${ }^{4}$

In recent years, significant improvements have been made to the accessibility of oral health care in New Hampshire. Since 2010, the number of public dental health clinics has increased from fifteen to seventeen with two more in development, and programs providing dental sealants (protective dental coatings) to students in high need schools have also expanded. ${ }^{5}$ New Hampshire was recently named one of five states to earn an " $A$ " grade for the use of sealants in children's preventive oral health care by the Pew Charitable Trusts, ${ }^{6}$ and one of three states to receive the maximum points possible. Additionally, in August 2014, a bill was passed that created a legislative study committee to "analyze and

\section{KEY FINDINGS}

Although New Hampshire is rated above the national average on most measures of pediatric oral health, performance varies substantially by county.

Access to adequate oral health care is particularly challenging for low-income families in the sparsely populated northern region of the state.

When oral health care becomes inaccessible, New Hampshire residents are resorting to the costly alternative of hospital emergency departments by the thousands.

Programs that address oral health care access issues by bringing services to those with the greatest need, such as school-based dental sealant programs and mobile dental care units, are among current efforts to improve oral health across the state.

Data regarding oral health care in New Hampshire are both limited and difficult to obtain. In order to fully understand what is and is not working well and to address access issues in our state, more data must be routinely collected and made publicly available.

evaluate barriers to and coverage for dental care for underserved New Hampshire residents" ${ }^{\prime 7}$ in order to increase oral health care access for New Hampshire residents most at risk of inadequate care.

Oral health care access issues do remain nevertheless. This brief offers an overview of the current state of oral health care in New Hampshire. 


\section{The State of Oral Health in New Hampshire}

\section{Children}

In a 2011 to 2012 national survey, 84.9 percent of New Hampshire children were reported to have received a preventive dental visit compared with 77.2 percent nationally, and 81.7 percent were reported to be in either excellent or good oral health compared with 71.3 percent nationally. On both survey measures, New Hampshire's performance was significantly higher than national performance. ${ }^{8}$ Additionally, the percentage of New Hampshire's third grade students with evidence of either treated or untreated tooth decay has dropped from 43.6 percent in 2009 to 35.4 percent in 2014 . $^{9,10}$

Despite the relatively positive state of oral health care in New Hampshire and its recent improvements, more than a third of the state's children still experience tooth decay, one of the most preventable childhood diseases.

Despite the relatively positive state of oral health care in New Hampshire and its recent improvements, more than a third of the state's children still experience tooth decay, one of the most preventable childhood diseases.

Performance on key surveillance measures of pediatric oral health, including 1) evidence of tooth decay, either treated or untreated, or 2) untreated tooth decay specifically, varies substantially across the state. In 2014, Coös County had the highest rate of tooth decay among third graders with over half showing evidence of this condition (56.0 percent). Strafford County third graders had the highest rate of untreated decay at 14.2 percent, up from 13.7 percent in 2009. During that same time period, Coös County experienced a substantial decrease in those with untreated decay from 30.7 percent in 2009 to 14.0 percent in 2014, yet still has the second highest rate of untreated decay in the state. Rates of untreated decay were below 10 percent in all remaining counties with the exception of Grafton at 11.7 percent (Figure 1). ${ }^{11,12}$

Approximately 8 percent of third graders statewide were found in need of treatment prior to their next regularly scheduled dental appointment, and 1 percent were found in need of urgent treatment, a condition characterized by "infection, pain, or swelling requiring dental care within the next several days" ${ }^{13}$ In four New Hampshire counties-Strafford, Coös, Grafton, and Hillsborough-more than one in ten third graders needed treatment. The greatest need for treatment was found in Strafford County at 14.2 percent, followed by Coös County at 12.5 percent (also down from an alarming 31.1 percent in 2009, however). Sullivan and Hillsborough County third graders had the greatest need for urgent treatment at 1.8 and 1.7 percent respectively. ${ }^{14}$ See Figure 2.

\section{Adults}

Many New Hampshire adults also report inadequate oral health care, particularly in the state's northernmost county. Consistently, over the past decade, a quarter of New Hampshire adults report that they have not visited a dentist or dental clinic in over a year. In 2012, just over one in ten adults statewide (10.2 percent) reported that it had been five years or more since their last visit; in Coös County, the percentage was more than double that of the state as a whole (22.0 percent). Coös County also reported the lowest percentage of adults with no permanent teeth removed, a measure for which a higher percentage is desirable ( 36.5 percent compared with 56.0 percent statewide), and the highest percentage of adults with all permanent teeth removed, a measure for which a lower percentage is desirable (11.4 percent compared with 4.6 percent statewide), due to tooth decay or gum disease. ${ }^{15}$ In addition to the impact tooth loss has on self-esteem and quality of life, it can lead to misalignment and wear and tear on remaining teeth. ${ }^{16,17}$

\section{Older Adults}

New Hampshire's elderly population is on the rise, with over half a million residents or one-third of the state's population predicted to be over the age of 65 by 2030 , suggesting a growing need for services accommodating this population. ${ }^{18}$ In long-term or residential care settings, preventive oral health care interventions for the elderly have been found to significantly reduce the risk of serious, sometimes fatal illnesses such as pneumonia and respiratory disease. ${ }^{19}$ Access to care is also important for older adults living in their communities to reduce the risk of illness, infection, and low quality of life resulting from poor oral health. ${ }^{20}$ Dental services are excluded from basic Medicare coverage (Parts A and B) except when they are an integral part of a covered medical procedure. ${ }^{21}$

Among older adults participating in a 2014 survey (average age of 76 years) conducted at twenty-five randomly sampled senior centers and congregate meal 
FIGURE 1. UNTREATED DECAY AMONG NEW HAMPSHIRE'S THIRD GRADE STUDENTS BY COUNTY IN SCHOOL YEARS 2008-2009 AND 2013-2014 (NH DHHS, 2010; NH DHHS, 2014A).

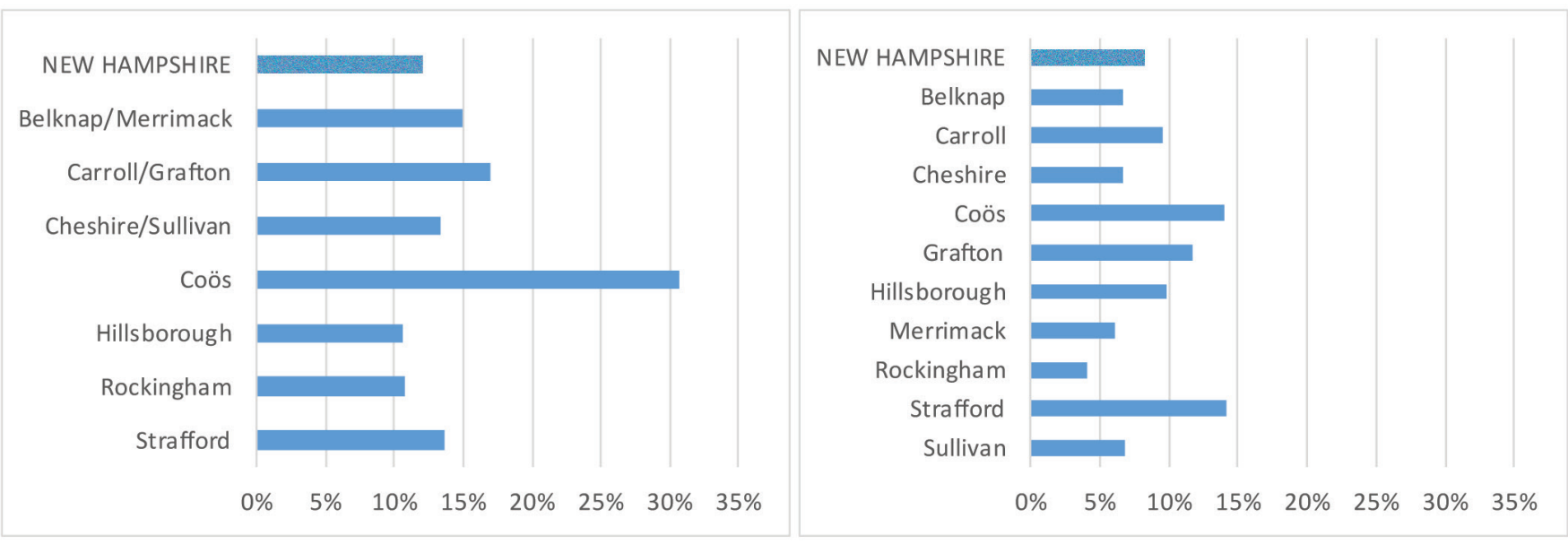

\section{FIGURE 2. NEED FOR DENTAL TREATMENT AND URGENT DENTAL TREATMENT PRIOR TO NEXT REGULARLY SCHEDULED DENTAL VISIT AMONG NEW HAMPSHIRE'S THIRD GRADE STUDENTS BY COUNTY IN SCHOOL YEARS 2008-2009 AND 2013-2014 (NH DHHS, 2010; NH DHHS, 2014A).}

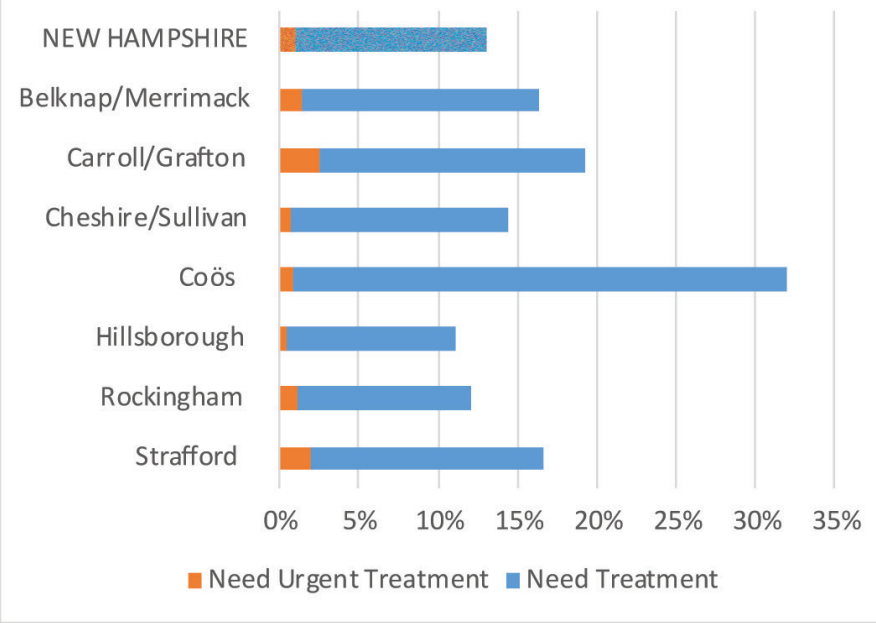

sites in New Hampshire, 15.9 percent had no remaining teeth and 5.2 percent had no remaining teeth and no dentures. Of those with remaining natural teeth, gum disease was present for 8.8 percent, and 22.1 percent were found to have untreated tooth decay. Low-income participant $s^{22}$ were significantly less likely than other participants to have a regular provider of routine dental care (47.3 percent compared with 68.0 percent) and significantly more likely to have no remaining natural

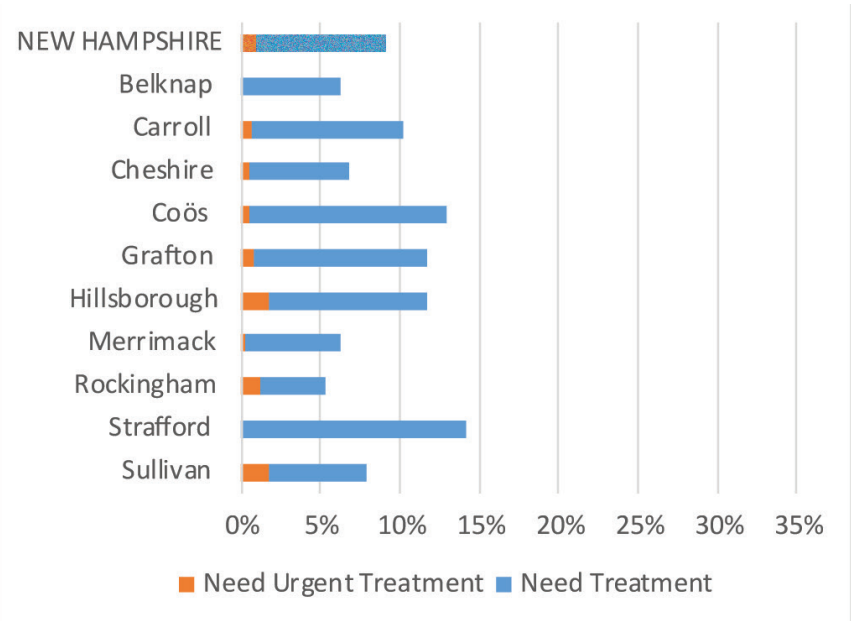

teeth (29.1 percent compared with 14.6 percent). Only 18.4 percent of all participants had insurance that helped to cover routine dental care, and significantly more participants in urban areas had some type of dental insurance (25.0 percent) compared with those in rural areas (14.9 percent). Significantly more participants in rural areas suffered from gum disease (11.9 percent compared with 2.9 percent) and resulting loose teeth (9.2 percent compared with 3.4 percent). ${ }^{23}$ 
These findings suggest a high level of need for access to dental insurance and to oral health care among New Hampshire's older adults, especially the state's lowincome older adults, and those living in rural areas.

\section{Adults and Children with Disabilities}

Poor oral health also puts adults and children with intellectual and developmental disabilities at an increased risk of developing respiratory infections. ${ }^{24}$ Oral health problems can impact disabled individuals' quality of life and ability to eat, sleep, and function without pain.

Daily oral hygiene can be made more difficult for those dependent on caregivers or those with oral aversions, as is common in individuals with autism. ${ }^{25}$ As a result, nationally, only 36.5 percent of severely disabled adults reported a dental visit compared to 53.4 percent of adults without disability. ${ }^{26}$ Although no data were available specific to oral health care for New Hampshire residents with disabilities, problems in general access to oral health care are critically important to resolve for this population due to the severity of the consequences. ${ }^{27,28}$

Over 29,000 New Hampshire public school students have disabilities, including approximately 2,400 with autism. ${ }^{29}$

\section{Barriers to Accessing Oral Health Care}

\section{Geographic Shortage Areas and Underserved Populations}

Access to oral health care is dependent on access to dental care providers, but the availability of dental care providers does not always meet the population's needs.

A federally designated geographical dental health professional shortage area (DHPSA) exists wherever a "rational area for the delivery of dental services" has a population to full-time equivalent dentist ratio of at least 5,000 residents for every 1 dentist. Areas with a poverty rate of at least 20 percent or a non-fluoridated water supply are considered "high need," and the minimum ratio drops to 4,000 residents for every 1 dentist for a DHPSA designation. In addition to geographic areas, the DHPSA designation may be applied to populations based on access barriers, to public or nonprofit facilities based on capacity to meet the needs of their catchment areas or target populations, and to correctional institutions with at least 250 inmates and a ratio of internees to full time equivalent dentists of at least 1,500 to $1 .{ }^{30}$ These multiple types of designation make it difficult to accurately represent DHPSAs on a map. Instead, Figures 3A and 3B display the geographical distribution of currently licensed New Hampshire general practice and pediatric dentists. ${ }^{31}$

All of New Hampshire's DHPSA designations are for specific populations and facilities rather than geographic areas.

The low-income populations in Plymouth, Northern Grafton, and throughout Coös County are designated as underserved. These designations indicate access issues related to low-income status above and beyond the dentist-to-population ratio.

The low-income populations in Plymouth, Northern Grafton, and throughout Coös County are designated as underserved. These designations indicate access issues related to low-income status above and beyond the dentist-to-population ratio. Additionally, with the exception of Cheshire, all New Hampshire counties have one or more facilities with the DHPSA designation, including Saco River Medical Group in Carroll County, Avis Goodwin Community Health Center in Strafford County, and Charlestown Family Medical Center and Newport Health Center in Sullivan County.

Although Cheshire County contains no DHPSAs, it has the fewest New Hampshire licensed dentists per 5,000 in the population as of 2014 at 1.7 compared with 2.9 statewide, and that number has decreased from 2.2 in 2009..$^{32,33}$ Sullivan County has the next fewest dentists per 5,000 in the population at 1.9. The remainder of New Hampshire counties have at least two dentists per 5,000 in the population, with Grafton, Merrimack, and Rockingham exceeding three (Figure 4). Again, it is important to note that New Hampshire's DHPSA designations are not based solely on this ratio.

It is also important to note that access to fluoridated water is low in New Hampshire relative to the rest of country. As of 2012, New Hampshire ranked $43^{\text {rd }}$ in the percentage of residents who use 
FIGURE 3A. ALL CURRENTLY LICENSED GENERAL PRACTICE AND PEDIATRIC DENTISTS IN NEW HAMPSHIRE (NH BDE, 2015).

New Hampshire Dentists, 2014

$\checkmark$ General Practice

$\diamond$ Pediatric Dentistry

- Roads

White Mountain National Forest Lakes



Source: NH Board of Dental Examiners 
FIGURE 3B. GENERAL AND PEDIATRIC DENTISTS IN THE SOUTHEAST REGION OF NEW HAMPSHIRE (NH BDE, 2015).

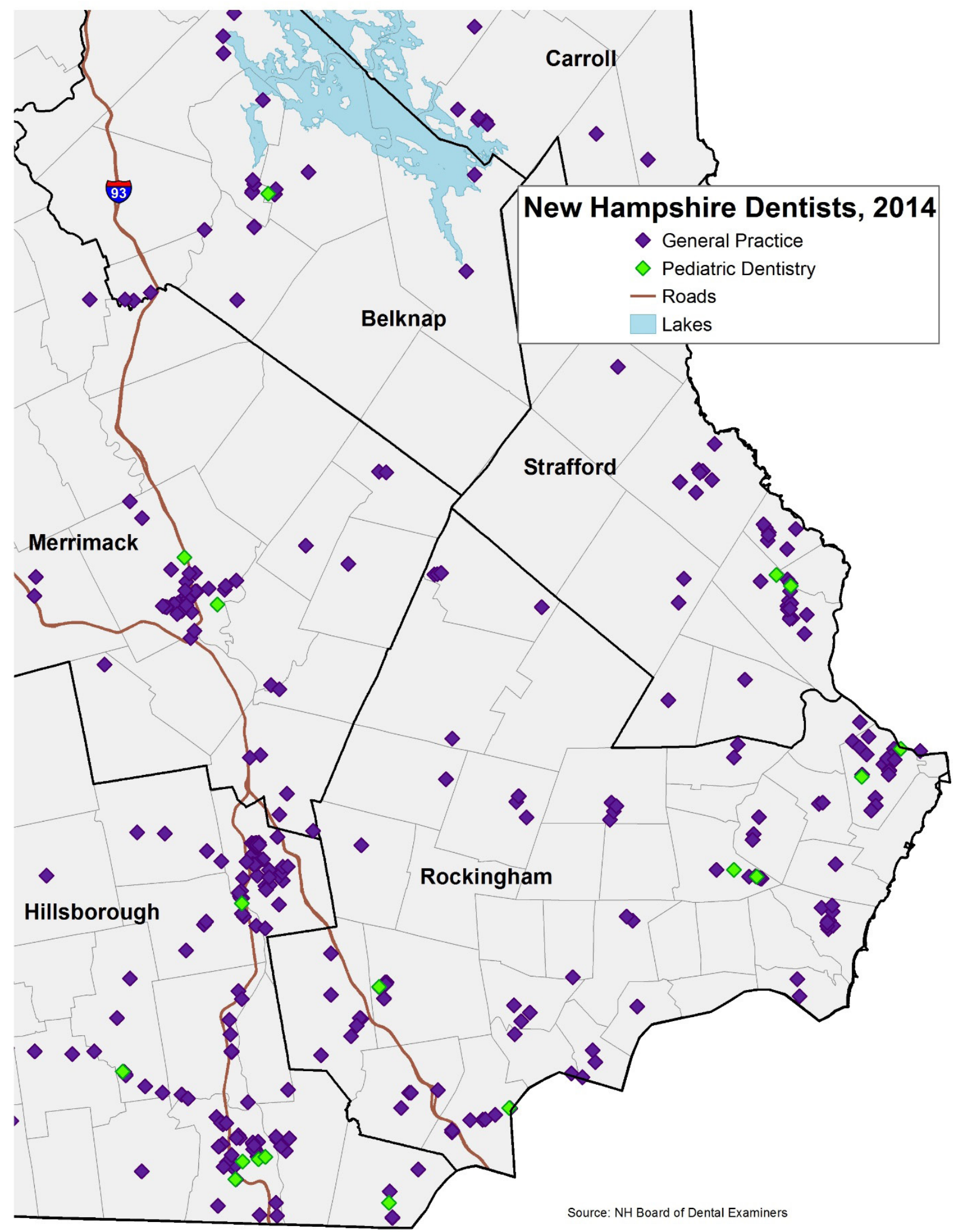


FIGURE 4. NEW HAMPSHIRE LICENSED DENTISTS PER 5,000 RESIDENTS BY COUNTY, 2015 (NH BDE, 2015; U.S. CENSUS BUREAU, 2014A).

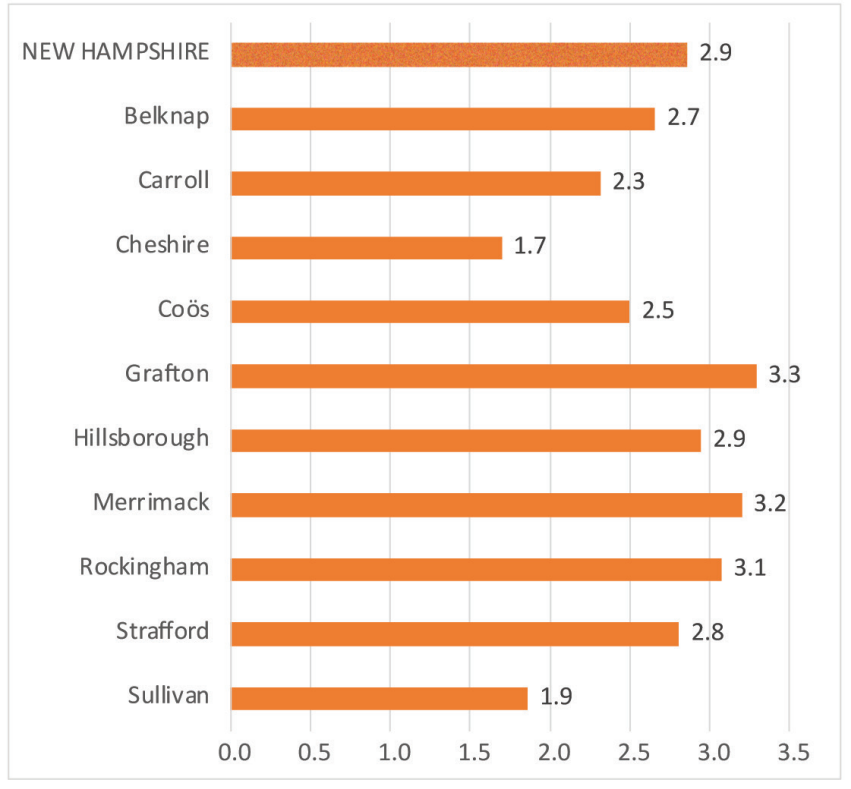

community water systems with access to a fluoridated water supply at 46 percent compared to 75 percent nationally. ${ }^{34}$ The Centers for Disease Control and Prevention recommends fluoridation of public water supplies to aid in the prevention of tooth decay among all age groups. ${ }^{35}$ At 8 percent, Coös County has the lowest rate of fluoridated public water systems, followed by 20 percent in Cheshire County and 26 percent in Rockingham County. All remaining New Hampshire Counties exceed 30 percent. ${ }^{36}$

\section{Lack of Adequate Dental Insurance Coverage} In 2011, 16,656 New Hampshire residents submitted medical insurance claims for 24,481 medical visits due to oral health conditions such as gum disease and diseases of the hard and soft tissues of the teeth. ${ }^{37}$ In 2009, there were 15,797 regional hospital emergency department discharges for non-traumatic dental conditions among New Hampshire residents. Although more recent data were not available, this figure was fairly stable over the five preceding years. ${ }^{38}$

An analysis of emergency department visits by New Hampshire residents for non-traumatic dental conditions between 2001 and 2008 found that the majority occurred between 6:00 a.m. and 6:00 p.m. and were evenly distributed throughout the week, when many dental practices would be open for business. Furthermore, the authors found that an estimated 44 to 51 percent of these visits were self-pay, suggesting that a lack of dental insurance is one of the primary factors steering dental patients into hospital emergency departments. Charges for emergency department services for dental conditions totaled $\$ 5.9$ million in 2007 , up from $\$ 1.8$ million in $2001 .^{39}$

All of these findings indicate a large volume of oral health care provided and paid for outside of the dental services system, in settings ill-equipped to respond to oral health treatment needs, at a much higher cost than routine preventive care, early diagnosis, and timely treatment.

Nationally, between 1997 and 2010, private health insurance coverage among non-elderly adults fell from 74.0 percent to 65.8 percent, and public insurance coverage (that is, Medicaid) increased from 5.4 to 8.3 percent. Concurrently, dental care utilization declined for this population with the exception of the wealthiest, with the steepest drops occurring during the Great Recession. ${ }^{40}$ Previous research indicates that privately insured individuals are 1.5 times more likely than those covered by public health plans to obtain routine oral health care, ${ }^{41}$ yet in keeping with national trends, an increasing number of New Hampshire residents are covered by the latter. Medicaid enrollment in New Hampshire rose from 106,636 in 2006 to 138,518 in $2011 .^{42}$ As of 2013, 30.0 percent of our state's children and 7.0 percent of adults were enrolled in Medicaid. ${ }^{43}$ By 2018, access to comprehensive dental benefits among children is projected to rise by 15 percent compared to 2010 through Medicaid, health insurance exchanges, and employer sponsored insurance with implementation of provisions of the Affordable Care Act. In the same timeframe, the increase for adults is projected at 5 percent, primarily through Medicaid. ${ }^{44}$

There is no federal requirement for adult dental coverage under Medicaid, and coverage therefore varies state to state. In New Hampshire, Medicaid dental coverage for adults over age 21 is limited to treatment of acute pain or infection. For children enrolled in Medicaid, however, dental coverage is comprehensive, and is federally required to include early periodic screening, diagnosis, and treatment. ${ }^{45}$ 


\section{Availability of Pediatric Dentists and Dentists Accepting Medicaid-Enrolled Children}

Between 2002 and 2012, the number of dental care providers treating Medicaid patients under age 21 statewide increased from 294 to 388, and the number of Medicaid-enrolled children accessing non-orthodontic dental treatment increased from 18,457 to 54,772 . These increases are remarkable, yet they translate to only 57 percent of Medicaid-enrolled children accessing dental care. In 2012, of those accessing care, approximately 80 percent were served by a total of 40 primarily pediatric dental practices. ${ }^{46}$ Although we were unable to obtain location data for New Hampshire dentists accepting Medicaid-enrolled children, it appears that the greatest gains in access have been where providers were already serving Medicaid-enrolled children in large numbers, and therefore have likely been experienced in the southern part of the state where populations of Medicaidenrolled children are concentrated.

New Hampshire currently has only forty-six licensed pediatric dentists, seven of whom may not be actively practicing in the state, to serve approximately 271,000 residents under the age of 18 .

A study conducted in New Hampshire with 12,964 Medicaid-enrolled children found that those seen by pediatric dentists were 26 percent more likely to have had at least two dental exams over a one-year period, 19 percent more likely to have received sealant applications, and 51 percent more likely to have received fluoride treatments than children seen by general dentists. ${ }^{47}$ However, New Hampshire currently has only forty-six licensed pediatric dentists, seven of whom may not be actively practicing in the state, ${ }^{48,49}$ to serve approximately 271,000 residents under the age of $18 .^{50}$ If thirty-nine pediatric dentists are both currently licensed and actively practicing in New Hampshire, this computes to a statewide ratio of 0.7 per 5,000 in the population of children under 18 .

The need for access to pediatric dentistry specialists, particularly those accepting children enrolled in Medicaid, remains high in the northern region of the state. As of 2013, although the greatest absolute numbers of Medicaid/CHIP enrolled children under age 18 lived in Hillsborough $(27,264)$ and Rockingham $(12,084)$ Counties, Coös and Carroll Counties had the highest enrollment rates at 53.1 percent and 47.5 percent, respectively. ${ }^{51,52}$ No actively licensed pediatric dentists report a primary professional address in either of these northern counties despite a combined child population of nearly $13,800 . .^{53}$

It is possible that the dwindling value of Medicaid reimbursement rates is discouraging providers from accepting new pediatric patients with Medicaid coverage. New Hampshire currently provides higher reimbursement rates for dental services than other New England states, yet adjusted for inflation, the real value of New Hampshire's average Medicaid reimbursement rates declined by 12 percent between 2003 and $2013 .^{54}$

\section{Income and Family Structure}

The out-of-pocket costs of dental services, as well as the cost of transportation to appointments, time spent out of work, and need for child care create additional barriers to care.

Thirty-seven percent of participants in a recent national survey reported that they or someone in their family had delayed a dental care visit due to the out-ofpocket expense..$^{55}$ In 2010, 7 percent of children ages 2 to 17 years nationwide, or 4.3 million children, reportedly lacked adequate oral health care because their families could not afford it. Children in households with an annual family income of less than $\$ 35,000$ were found less likely to have had a dental visit in the past six months compared to children in households with an annual family income over $\$ 35,000$ (53.5 percent compared with 66.8 percent) and more likely to have unmet dental care needs ( 9.4 percent compared with 5.5 percent).${ }^{56}$ Factors associated with financial stress, such as long work hours or a lack of assistance with child care, contribute to the underutilization of dental care. Even when such care is available for free and monetary incentives for care are offered, other responsibilities may be prioritized by immediate necessity. ${ }^{57}$

Single parents may have more difficulty taking time off of work, arranging for and covering the expense of transportation, and paying the outof-pocket costs of care than those parenting with partners. ${ }^{58,59}$ Among children in single parent households, 8.7 percent have been found to experience unmet dental care needs, compared with 5.7 percent in two parent households. ${ }^{60}$ 
In New Hampshire, 27.9 percent of all families with children under the age of 18 , or 40,576 families, are headed by single parents. ${ }^{61}$ Nearly one in ten of all families with children under the age of 18 (9.5 percent) have household incomes below the poverty threshold, which in 2014 was $\$ 24,008$ for a family of four with two children under $18 .^{62}$ Among families with children under 18 headed by single women, the poverty rate more than triples to 30.6 percent. ${ }^{63}$ Geographical distribution of providers aside, thousands of New Hampshire families are facing multiple barriers to accessing care related to household income and family structure.

County level poverty rates are highest in the northern region of the state, specifically in Coös County where 19.2 percent of families with children under age 18 have annual household incomes below the poverty threshold. Coös County also has the highest percentage of single parent families at 37.4 percent. ${ }^{64}$ Low-income and single parent headed families in Coös County face substantial barriers to accessing dental services and are at heightened risk for inadequate oral health care.

Figure 5 maps the location of general practice and pediatric dentists over district eligibility rates for the Free and Reduced Price Lunch program among public school students grades 1 through 12 in the 2013-14 school year. ${ }^{65}$ This is widely considered a valid proxy measure of low-income families in the population. ${ }^{66}$ Although in the southeastern part of the state there are pockets of high program eligibility, these areas are home to clusters of both general practice and pediatric dentists. The northern part of the state shows the largest contiguous stretch of high eligibility districts on the map, yet due to the sparseness of the population, few general practice dentists and no pediatric dentists are located there to meet the needs of children in low-income families.

\section{Addressing Barriers to Access}

Nationwide, including here in New Hampshire, there are initiatives underway to improve the oral health of children and adults. Minnesota, Alaska, and most recently Maine,${ }^{67}$ for example, have expanded the oral health care provider network available to their residents by creating a mid-level oral health care provider, the Dental Therapist. This expansion has increased access to oral health care providers, reduced wait-times for appointments, and reduced travel time to appointments, with
Mobile dental services are another example of bringing oral health care to the people and places of greatest need. There are a number of mobile dental units that travel throughout New Hampshire serving high risk populations.

a more pronounced impact in rural areas. ${ }^{68,69}$ Dental therapists are currently used in over 54 countries around the world, and are frequently school based, providing care to underserved children..$^{70,71}$

North Carolina's Into the Mouths of Babes early prevention program and New Hampshire's Healthy Smiles school-based sealant program bring oral health care to children outside of the dentist's office. Into the Mouths of Babes emphasizes early prevention by providing oral health care services in primary care physicians' offices, thereby broadening children's exposure to dental intervention programs. This program resulted in an almost six-fold increase in the number of patients gaining access to routine oral health care in its nine years in operations. ${ }^{72}$

New Hampshire's school-based dental sealant programs have demonstrated a decrease in tooth decay and need for dental treatment among students in participating high risk schools statewide. ${ }^{73,74}$ Additionally, primary care clinicians who have completed the Smiles for Life ${ }^{75}$ nationally approved training curriculum module on fluoride varnish application for prevention of tooth decay can now receive Medicaid reimbursement for provision of this service to pediatric patients. However, although New Hampshire has approved Medicaid reimbursement for fluoride varnish application in primary care settings, this strategy has not yet been fully implemented. The New Hampshire Oral Health Coalition is currently offering assistance and onsite training in primary care doctors' offices across the state in order to expand its adoption. ${ }^{76}$

Mobile dental services are another example of bringing oral health care to the people and places of greatest need. There are a number of mobile dental units that travel throughout New Hampshire serving high risk populations such as students enrolled in Medicaid, uninsured and underinsured adults, families living in transitional housing, and the elderly in residential care. See Box 1 on page 11 for examples of mobile units currently in operation around the state. 
FIGURE 5. ALL CURRENTLY LICENSED GENERAL PRACTICE AND PEDIATRIC DENTISTS IN NEW HAMPSHIRE OVERLAYING MAP OF ELIGIBILITY RATES FOR FREE AND REDUCED PRICE SCHOOL LUNCH (PROXY MEASURE OF LOW-INCOME FAMILIES IN THE POPULATION) (NH BDE, 2015; NH DOE, 2014)

Percent of Students Qualifying for Free and Reduced School Lunch

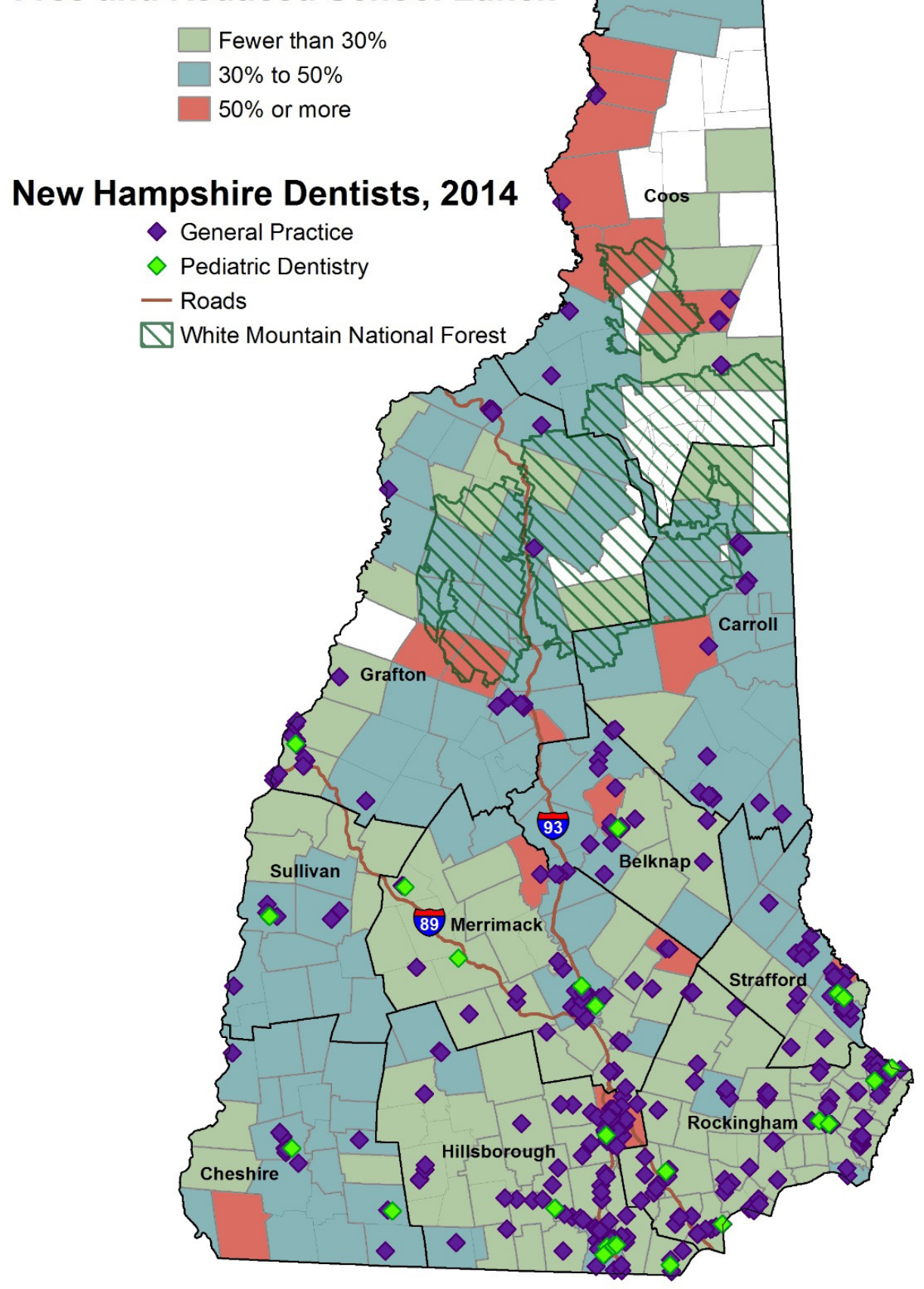




\section{Conclusion}

Although New Hampshire does very well on many key measures of oral health, there is substantial variation by county and by region, which suggests the need for further efforts to improve oral health care access in some areas of the state. Additionally, barriers to access persist for specific New Hampshire populations at higher risk for inadequate oral health care, particularly low-income families, children enrolled in Medicaid, the elderly, and individuals with disabilities. These barriers contribute to underutilization of routine preventive dental care and treatment services, including those to which children enrolled in Medicaid are entitled.

Innovative oral health care models that bring services to those with the greatest need, such as schoolbased programs, programs set in pediatricians' offices, and mobile dental units, may help to improve oral health care access across New Hampshire. Dental care workforce expansion is another approach to addressing gaps in access that has shown promise in other areas. Findings regarding the state of oral health among the general adult population in New Hampshire suggest that expansion of dental insurance coverage for adults should be considered as well, which in addition to improving oral health, may reduce the total cost of medical and emergency department claims for treatment of oral health conditions.

\section{End notes}

1. Susan O. Griffin et al., "Burden of Oral Disease among Older Adults and Implications for Public Health Priorities," American Journal of Public Health, vol. 102, no. 3 (2012): 411-418.

2. Aubrey Sheihan, "Dental Caries Affects Body Weight, Growth and Quality of Life in Pre-School Children," British Dental Journal, vol. 201, no. 10 (2006): 625-626.

3. Helen C. Gift, Susan T. Reisine, and Dina C. Larach, "The Social Impact of Dental Problems and Visits," American Journal of Public Health, vol. 82, no. 12 (1992): 1663-1668.

4. K. P. Ahluwalia et al., "Oral Disease Experience of Older Adults Seeking Oral Health Services," Gerodontology, vol. 27 (2009): 96-103.

5. New Hampshire Dental Society, "More to Smile About 2014" (Concord, NH: New Hampshire Dental Society, 2014).

6. Pew Charitable Trusts, "States Stalled on Dental Sealant Programs" (Washington, DC: The Pew Charitable Trusts, 2015).

\section{Box 1: Mobile Dental Units}

Mobile dental units are bringing oral health care directly to those in need. Below are some examples of this service delivery model currently operating in New Hampshire.

- The Ronald McDonald Care mobile unit travels to schools in the Concord area to serve children who have no dental insurance or have not been to the dentist in over a year. It is equipped to provide dental exams, full cleanings, $\mathrm{x}$-rays, fillings, and other services. More information at: www.rmhcene.org or (781) 733-7234.

- In northern New Hampshire, The Molar Express provides oral health education and dental services such as exams, cleanings, $\mathrm{x}$-rays, fillings, sealants, and even extractions to students in North Country schools in need of dental care who do not have a regular dentist, including the uninsured, the underinsured, and those enrolled in NH or VT Medicaid. They also provide services to residents of nursing homes in the area. More information at: www.nchenh. org/molar_express.php or (603) 259-3700.

- The Families First Mobile Health Care unit offers a range of health care and support services, including dental care, to people in unstable or temporary living situations in the Seacoast area. Medicaid and Medicare are accepted, and free or low-cost care is available to the uninsured. Designated stops include homeless shelters, transitional housing, and other locations where services for this population are provided. More information at: www. familiesfirstseacoast.org/health_care_for_ homeless.html or (603) 422-8208.

7. The New Hampshire General Court, An Act Establishing a Commission to Study Pathways to Oral Health Care in New Hampshire (Concord, NH: New Hampshire General Court, 2013), available at www.gencourt.state.nh.us/ legislation/2014/SB0193_HA.html.

8. Data Resource Center for Child and Adolescent Health, "National Survey of Children's Health 2011/12" (Child and Adolescent Health Measurement Initiative, 2012). 
9. Division of Public Health Services, New Hampshire 2008-09 Third Grade Health Smiles-Healthy Growth Survey: Oral Health and Body Mass Index Assessment of New Hampshire Third Grade Students (Concord, NH: New Hampshire Department of Health and Human Services, 2010), available at www.dhhs.nh.gov/dphs/bchs/rhpc/oral/ documents/thirdgradesurvey.pdf.

10. Division of Public Health Services, New Hampshire 2013-2014 Third Grade Healthy Smiles-Healthy Growth Survey (Concord, NH: New Hampshire Department of Health and Human Services, 2014a), available at www.dhhs.nh.gov/dphs/bchs/rhpc/oral/documents/ thirdgradesurvey2014.pdf.

11. Division of Public Health Services, 2010.

12. Division of Public Health Services, 2014a.

13. Ibid.

14. Ibid.

15. New Hampshire HealthWRQS, "Behavioral Risk Factor Surveillance System” (Durham, NH: Institute for Health Policy and Practice, University of New Hampshire, 2012).

16. David S. Brennan, A. John Spencer, and Kaye F. RobertsThomson, "Tooth Loss, Chewing Ability, and Quality of Life," Quality of Life Research, vol. 17, no. 2 (2008): 227-235.

17. Ilona Fotek, "Malocclusion of Teeth," MedlinePlus. Last modified February 25, 2014, available at www.nlm.nih.gov/ medlineplus/ency/article/001058.htm.

18. Stephen Norton, "New Hampshire's Silver Tsunami: Aging and the Health Care System" (Concord, NH: New Hampshire Center for Public Policy Studies, 2011).

19. Petteri Sjögren et al., "A Systematic Review of the Preventative Effect of Oral Hygiene on Pneumonia and Respiratory Tract Infection in Elderly People in Hospitals and Nursing Homes: Effect Estimates and Methodological Quality of Randomized Controlled Trials," Journal of the American Geriatrics Society, vol. 56, no. 11 (2008): 2124-2130.

20. Ahluwalia et al., 2009.

21. Centers for Medicare and Medicaid Services, Medicare Dental Coverage (Baltimore, MD: Centers for Medicare and Medicaid Services, 2013), available at www.cms.gov/ Medicare/Coverage/MedicareDentalCoverage/index. html? redirect=/MedicareDentalcoverage.

22. "Low-income" refers here to those participating in the means-tested USDA Commodity Supplemental Food Program for people ages 60 and up (NH DHHS, 2014b). More information at www.astdd.org/state-activitiesdescriptive-summaries/?id=56.

23. Division of Public Health Services, Oral Health Survey of New Hampshire Older Adults, 2014 (Concord, NH: New Hampshire Department of Health and Human Services
Division of Public Health Services, 2014b), available at www. dhhs.state.nh.us/dphs/bchs/rhpc/oral/documents/olderadults-2014.pdf.

24. Catherine J. Binkley, et al., "Oral Microbial and respiratory Status of Persons with Mental Retardation/ Intellectual and Developmental Disability: An Observational Cohort Study," Oral Surgery, Oral Medicine, Oral Pathology, Oral Radiology, and Endodontology, vol. 108, no. 5 (2009): 722-731.

25. Kenneth W. Norwood Jr. and Rebecca L. Slayton, "Oral Health Care for Children with Developmental Disabilities," Pediatrics, vol. 131, no. 3 (2013): 614-619.

26. Joan Earle Hahn et al., "Infusing Oral Health Care into Nursing Curriculum: Addressing Preventative Health in Aging and Disability," Nursing Research and Practice, vol. 2012 (2012).

27. Dynamic Dental Educators, "Accessing Dental Care: Home Study Course \#5039” (Tampa, FL: Dynamic Dental Educators, 2003).

28. Griffin et al., 2012.

29. Ralph Tilton, Statewide Census by Disability (Concord, NH: New Hampshire Department of Education, 2013), available at http://education.nh.gov/instruction/special_ed/ documents/child_count_october_2013.pdf.

30. Health Resources and Services Administration, Dental HPSA Designation Overview (Washington, DC: U.S. Department of Health and Human Services, 2015).

31. New Hampshire Board of Dental Examiners, personal communication, "List of New Hampshire’s Actively Licensed Dentists," January 15, 2015.

32. Ibid.

33. R. Tappin and S. Norton, "Dental Services and Workforce in New Hampshire" (Concord, NH: New Hampshire Center for Public Policy, 2010), available at www.nhpolicy. org/UploadedFiles/Reports/nh_dental__workforce_ october2010.pdf

34. Centers for Disease Control and Prevention, “2012 Water Fluoridation Statistics," available at www.cdc.gov/ fluoridation/statistics/2012stats.htm.

35. U.S. Department of Health and Human Services Federal Panel on Community Water Fluoridation, 2015. "U.S. Public Health Service Recommendation for Fluoride Concentration in Drinking Water for the Prevention of Dental Caries" available at www.publichealthreports.org/documents/ PHS_2015_Fluoride_Guidelines.pdf.

36. Centers for Disease Control and Prevention, 2015, "My Water's Fluoride" available at https://nccd.cdc.gov/DOH_ MWF/Default/CountyList.aspx? state=New\%20Hampshire\& stateid $=33 \&$ stateabbr $=\mathrm{NH} \&$ reportLevel $=2$. 
37. Josephine Porter, "New Hampshire Comprehensive Health Care Information System, Aggregated Data” (Durham, NH: Institute for Health Policy and Practice at the University of New Hampshire, 2014).

38. New Hampshire Department of Health and Human Services, Personal Communication, "New Hampshire Hospital Discharge data, 2010," April 5, 2015.

39. Ludmila Anderson, et al., "Utilization of Hospital Emergency Departments for Non-Traumatic Dental Care in New Hampshire, 2001-2008," Journal of Community Health, vol. 36, no. 4 (2011): 513-516.

40. Thomas P. Wall, Marko Vujicic, and Kamyar Nasseh, "Recent Trends in the Utilization of Dental Care in the United States," Journal of Dental Education, vol. 76, no. 8 (2012): 1020-1027.

41. Leighton $\mathrm{Ku}$, "Medical and Dental Care Utilization and Expenditures under Medicaid and Private Health Insurance," Medical Care Research and Review, vol. 66, no. 4 (2009): 456-471.

42. Office of Medicaid Business and Policy, New Hampshire Medicaid Annual Report State Fiscal Year 2011 (Concord, NH: New Hampshire Department of Health and Human Services, 2013), available at www.dhhs.nh.gov/ombp/ documents/medicaid11.pdf.

43. "New Hampshire: Health Coverage and Uninsured," Henry J. Kaiser Family Foundation, http://kff.org/statecategory/health-coverage-uninsured.

44. Kamyar Nasseh, Marko Vujicic, and Amanda O'Dell, "Affordable Care Act Expands Dental Benefits for Children But Does Not Address Critical Access to Dental Care Issues" (Chicago, IL: American Dental Association Health Policy Institute, 2013), available at www.ada.org/ /media/ADA/ Science\%20and\%20Research/HPI/Files/HPIBrief_0413_3.pdf.

45. New Hampshire Department of Health and Human Services (2011), "New Hampshire Medicaid Annual Report" available at www.dhhs.nh.gov/ombp/documents/ medicaid11.pdf.

46. Margaret Snow, "Medicaid Dental Access Summary (Birth to 21 Years), State Fiscal Years 2002 through 2012" (Concord, NH: Dental Access Alliance, 2013).

47. Donald Chi and Peter Milgrom, "Preventative Dental Service Utilization for Medicaid-Enrolled Children in New Hampshire: A Comparison of Care Provided by Pediatric Dentists and General Dentists," Journal of Health Care for the Poor and Underserved, vol. 20, no. 2 (2009): 458-472.

48. Seven of the currently licensed pediatric dentists did not report a practice address or phone number within the state of New Hampshire.

49. NH Board of Dental Examiners, 2015.
50. U.S. Census Bureau, Table PEPAGESEX: Annual Estimates of the Resident Population for Selected Age Groups By Sex for the United States, Counties, and Puerto Rico Commonwealth and Municipios (Washington, DC: U.S. Census Bureau 2014a).

51. New Hampshire Department of Health and Human Services, personal communication to author, "Medicaid and CHIP Enrollment by County," October 6, 2014.

52. Although Medicaid covers children up to age 21, the best available population data are for children under 18 . Therefore, Medicaid enrollment rates were computed for the population of children under 18 only.

53. NH Board of Dental Examiners, 2015.

54. Kamyar Nasseh and Marko Vujicic, "Are Medicaid and Private Dental Insurance Payment Rates for Pediatric Dental Care Services Keeping Up With Inflation?" (Chicago, IL: American Dental Association Health Policy Institute, 2014), available at www.ada.org/ /media/ADA/Science\%20and\%20 Research/HPI/Files/HPIBrief_1214_2.ashx.

55. Children's Dental Health Project, "QuickRead Report" (Washington, DC: Children's Dental Health Project, 2015).

56. Barbara Bloom, Robin A. Cohen, and Gulnur Freeman, Summary Health Statistics for U.S. Children: National Health Interview Survey, 2010, Series 10, Number 250 (Washington, DC: National Center for Health Statistics, 2011).

57. Nancy Nairi Maserejian et al., "Underutilization of Dental Care When It Is Freely Available: A Prospective Study of the New England Children's Amalgam Trial," Journal of Public Health Dentistry, vol. 68, no.3 (2008): 139-148.

58. Ibid.

59. Bloom, Cohen, and Freeman, 2011.

60. Ibid.

61. U.S. Census Bureau, American Community Survey, Table DP02, Selected Social Characteristics, 5-Year Estimate 2009-2013 (Washington, DC: U.S. Census Bureau, 2014c).

62. U.S. Census Bureau (2014), Poverty Thresholds, available at www.census.gov/hhes/www/poverty/data/threshld.

63. U.S. Census Bureau, American Community Survey, Table DP03, Selected Economic Characteristics, 5-Year Estimate 2009-2013 (Washington, DC: U.S. Census Bureau, 2014b).

64. Ibid.

65. New Hampshire Department of Education, Free/ Reduced School Lunch Eligibility, 2013-2014 (Concord, NH: New Hampshire Department of Education Division of Program Support, 2014), available at www.education.nh.gov/ data/documents/lunch_school13_14.pdf.

66. Free and Reduced Price Lunch eligibility was used as a proxy measure because the data were available for smaller geographic units than U.S. Census Bureau poverty estimates. 
67. "Pew Commends Maine for Authorizing Dental Hygiene Therapists," Pew Charitable Trusts. Last modified April 29, 2014, available at www.pewtrusts.org/en/about/news-room/ press-releases/2014/04/29/pew-commends-maine-forauthorizing-dental-hygiene-therapists.

68. Jay W. Friedman and Kavita R. Mathu-Muju, "Dental Therapists: Improving Access to Oral Health Care for Underserved Children," American Journal of Public Health, vol. 104, no. 6 (2014): 1005-1009.

69. Minnesota Board of Dentistry, Early Impacts of Dental Therapists in Minnesota (St. Paul, Minnesota: Minnesota Department of Health, 2014), available at http://mn.gov/healthlicensing-boards/images/2014DentalTherapistReport.pdf.

70. Friedman and Mathu-Muju, 2014.

71. David A. Nash et al., "A Review of the Global Literature on Dental Therapists," Community Dentistry and Oral Epidemiology, vol.42 (2014): 1-10.

72. Andrew Snyder, "Increasing Access to Dental in Medicaid: Targeted Programs for Four Populations" (CA: California Healthcare Foundation, 2009).

73. NH DHHS, 2010.

74. Division of Public Health Services, 2014a.

75. Smiles for Life offers a national training curriculum for primary care clinicians seeking to integrate oral health care into primary care settings. More information at www. smilesforlifeoralhealth.org.

76. New Hampshire Oral Health Coalition, personal communication, "Oral health care access in New Hampshire - Statement on Smiles for Life," August 17, 2015.

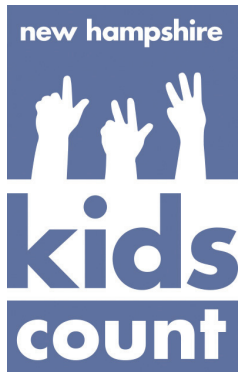

Improving the lives of all children by advocating for public initiatives that make a real difference

For over 27 years, NH Kids Count has assembled the most comprehensive data on child well-being in the state. This data provides the foundation for smart policy decisions that strengthen our families and communities.

\section{Delta Drive $\bullet$ Concord, NH 03301}

(603) 225-2264

nhkidscount.org

\section{About the Authors}

Eleanor M. Jaffee, $\mathrm{PhD}$, is senior evaluation research associate at the Carsey School of Public Policy and a research assistant professor of Social Work at the University of New Hampshire (eleanor.jaffee@unh.edu).

Joan Widmer, RN, ASN, BA, MSBA, is a certified emergency nurse in a Level III Trauma Center who has just completed her MS in nursing in evidence based practice at the University of New Hampshire (jwidmer56@gmail.com).

Lisa I. Speropolous, MS, is a doctoral candidate in sociology at the University of New Hampshire and a research assistant at the Carsey School of Public Policy (lis@unh.edu).

The maps in this paper were created by Barbara Cook, M.S. Geographic Information Systems Technician at the Carsey School of Public Policy.

\section{Acknowledgements}

This study was commissioned by NH Kids Count. We thank Executive Director Ellen Fineberg, Policy Director Erika Argersinger, and other staff and partners for providing guidance in its conceptualization, resources for gathering secondary data, and helpful comments and suggestions on the draft of this brief. We also thank our Carsey School of Public Policy colleagues: Curt Grimm, deputy director; Laurel Lloyd, communications coordinator; and Mary E. Barba, research assistant. Support for this project was provided by Pew Charitable Trusts.

\section{TI University of New Hampshire Carsey School of Public Policy}

The Carsey School of Public Policy conducts policy research on vulnerable children, youth, and families and on sustainable community development. We give policy makers and practitioners timely, independent resources to effect change in their communities.

$$
\begin{aligned}
& \text { Huddleston Hall • } 73 \text { Main Street • Durham, NH } 03824 \\
& \text { (603) 862-2821 }
\end{aligned}
$$

TTY UsERs: DIAL 7-1-1 OR 1-800-735-2964 (RELAY N.H.)

$$
\text { carsey.unh.edu }
$$

